\title{
Predicting the potential effect of E484K mutation on the binding of 28 antibodies to the spike protein of SARS-CoV-2 by molecular dynamics simulation and free energy calculation
}

Leyun $\mathrm{Wu}^{1,2, \#}$, Cheng Peng ${ }^{1,2, \#}$, Zhijian $\mathrm{Xu}^{1,2, *}$, Weiliang $\mathrm{Zhu}^{1,2, *}$

${ }^{1}$ CAS Key Laboratory of Receptor Research; Drug Discovery and Design Center, Shanghai Institute of Materia Medica, Chinese Academy of Sciences, Shanghai, 201203, China

${ }^{2}$ School of Pharmacy, University of Chinese Academy of Sciences, No.19A Yuquan Road, Beijing, 100049, PR China

${ }^{\#}$ These authors contributed equally to this work.

"To whom correspondence should be addressed.

Phone: +86-21-50806600-1201 (Z.X.), +86-21-50805020 (W.Z.),

E-mail: zjxu@ simm.ac.cn (Z.X.), wlzhu@ simm.ac.cn (W.Z.).

ORCID:

Zhijian Xu: 0000-0002-3063-8473

Weiliang Zhu: 0000-0001-6699-5299 


\begin{abstract}
Vaccines and antibody therapeutic are needed to fight the severe acute respiratory syndrome coronavirus 2 (SARS-CoV-2) that has spread since 2020. Experimental studies have shown that the E484K variant may escape the neutralization of antibodies. To explore the potential impact of E484K mutation on the antibody binding affinity, we calculated the binding free energy of 28 antibodies to the wild type and K484 mutant of the spike protein of SARS-CoV-2. We found that $71 \%$ of the antibodies show lower binding affinity to the E484K mutant, indicating the highly possible immune escape risk of the mutated virus. Further analysis revealed that the other mutations, e.g. F490 and V483, are also likely to cause immune escape.
\end{abstract}

Key Words: COVID-19; immune escape; E484K; binding free energy 


\section{INTRODUCTION}

The COVID-19 pandemic caused by SARS-CoV-2 has presented a global health emergency with over 106 million confirmed cases and over 2 million deaths worldwide since early $2020^{[1]}$. Without specifically effective chemical drug available to date, vaccines and antibody therapeutics have played a great role in fighting against SARSCoV-2, which brings hope to people to overcome the COVID-19 epidemic. Particularly, the single and combination monoclonal antibody $(\mathrm{mAb})$ therapeutics has attracted great concerns. However, current antibodies are mainly developed based on the initial SARSCoV-2 identified at the end of 2019. During the last year, the SARS-CoV-2 has been evolving and considerable mutants have occurred, including variants with an E484K mutation that recently appeared in UK, South Africa and Brazil. For instance, Novavax vaccine (NVX-CoV2373) ${ }^{[2]}$, which shows high effective rates of $96 \%$ and $86 \%$ for the common strains of SARS-CoV-2 and the UK variant, respectively. However, the vaccine has greatly reduced its effective rate to $60 \%$ and $\leq 50 \%$ for South African variant in the HIV-negative population and the entire population including HIV-positive people, respectively. Therefore, the existing vaccines and mAbs may have risks of immune evasion.

Due to the potential implications in vaccination and passive immune therapies, E484K has received particular attention ever since. Experiments in vitro have shown that the E484K substitution occurs when the SARS-CoV-2 is co-incubated in a highly neutralizing plasma from a COVID-19 convalescent patient, which leads to strong resistance to plasma neutralization ${ }^{[3]}$. Recent emergence of new SARS-CoV-2 variants B.1.1.33, P1 and P2, which were identified as the E484K mutation in the Brazilian territory, are of serious concern due to the possibility of escaping from neutralizing antibodies $^{[4]}$. Additionally, the latest research found that the E484K mutation on the spike protein impairs the efficacy of current mAbs targeting the angiotensin-converting enzyme 2 (ACE2) binding site ${ }^{[5]}$.

The entry of SARS-CoV-2 into its target cells depends on attachment of the receptor- 
binding domain (RBD) of the viral transmembrane spike protein to ACE2. Hence, the RBD of the SARS-CoV-2 spike is a dominant target of neutralizing antibodies and a focal point of vaccine design. Crystal structure shows the glutamic acid in position 484, which is at the interface of ACE2-RBD, has no contact with other monomers of spike protein (Figure S1), thus it has no direct effect on the RBD conformational transition. In addition, studies have indicated that the E484K mutation only led to slightly increased binding affinity for ACE2-RBD ${ }^{[6]}$. Although current researches suggest that the E484K enhances the viral escape from immune system, the role of E484K in antibody neutralization is still obscure.

To predict the potential effect of the E484K mutation on antibody neutralization and to better characterize how significant the mutation affects the binding affinity of the $\mathrm{RBD}$ to mAbs, we recently calculated the binding free energy of mAb-RBD by molecular dynamics simulation with MM/GBSA method. We searched the Protein Data Bank and obtained 91 crystal structures of SARS-CoV-2 spike protein with antibodies, of which 28 antibodies bound to the ACE2-RBD interface and contact with E484. From the analysis of molecular dynamics simulations, we found that five antibodies show the same binding affinity to the E484K mutant as to the wild type, three antibodies shows higher binding affinity to the E484K mutant, but the other 20 antibodies have reduced their binding affinity to the mutated RBD, alarming that E484K mutant might have stronger ability to escape from most of the antibodies than wild type.

\section{RESULTS AND DISCUSSION}

\section{Analysis of binding free energy}

To explore the impact of E484K mutation on the antibody binding affinity $(\boldsymbol{\Delta} \mathbf{G})$ of SARS-CoV-2 spike RBD, we calculated and compared $\Delta \mathbf{G}$ for 28 pairs of antibodyRBD complex by MM/GBSA based on 20 ns molecular dynamics simulations (Table

1). As shown in Figure $1\left(\boldsymbol{\Delta} \boldsymbol{\Delta} \mathbf{G}=\boldsymbol{\Delta} \mathbf{G}_{\mathbf{E 4 8 4}} \mathbf{K}-\boldsymbol{\Delta} \mathbf{G w T}\right)$, there are 20 systems, such as 
$7 \mathrm{~K} 90(\mathrm{C} 144, \boldsymbol{\Delta} \boldsymbol{\Delta} \mathbf{G}=49.24 \pm 1.25 \mathrm{kcal} / \mathrm{mol}){ }^{[7]}$ and $7 \mathrm{~K} 8 \mathrm{~W}(\mathrm{C} 119, \Delta \boldsymbol{\Delta} \mathbf{G}=19.68 \pm 0.68$ $\mathrm{kcal} / \mathrm{mol})^{[7]}$, show lower binding affinity of E484K than wild type, indicating that the neutralization ability of most RBD-targeted antibodies $(\sim 74 \%)$ are impaired by the specific substitution of E484K. Recently, Hansen et al. has found that the neutralization $\mathrm{IC}_{50}$ of REGN10933 (6XDG) ${ }^{[8]}$ on the E484K mutant and $\mathrm{SA} \Delta 9$ (B.1.351) variant is 10.5 and 58.8 times $^{[5]}$ lower than that of the wild type, respectively, which is consistent with our MM/PBSA results (Table1). And another studies also indicates that S2M11 $(7 \mathrm{~K} 43)^{[9]}$ possesses lower neutralization ability in E484K mutant.

It is also important to note that two antibodys in the 28 antibodies, viz. 52/298 and C104, possess higher binding affinities caused by E484K. As shown in Table 1, the

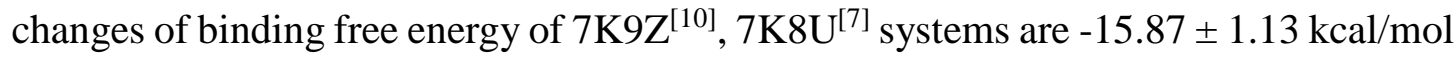
and $-11.55 \pm 0.62 \mathrm{kcal} / \mathrm{mol}$, respectively. Five systems, 7K8Y(C121) ${ }^{[7]}, 7 \mathrm{CDJ}(\mathrm{P} 2 \mathrm{C}-$ $1 \mathrm{~A} 3)^{[11]}, \quad 7 \mathrm{C} 8 \mathrm{~W}\left(\right.$ Synthetic nanobody MR17) ${ }^{[12]}, \quad 6 \mathrm{XKQ}(\mathrm{CV} 07-250)^{[13]}$ and 6XE1(CV30) $)^{[14]}$ have $\Delta \Delta \mathbf{G}$ of $2.70 \pm 0.72 \mathrm{kcal} / \mathrm{mol}, 1.95 \pm 0.64 \mathrm{kcal} / \mathrm{mol}, 2.50 \pm 0.85$ $\mathrm{kcal} / \mathrm{mol}, 4.14 \pm 0.92 \mathrm{kcal} / \mathrm{mol}$ and $0.45 \pm 0.87 \mathrm{kcal} / \mathrm{mol}$, respectively, indicating that the neutralization ability of these antibodies are insensitive to E484K mutation.

\section{Role of E484}

To further explore the mechanism of E484K on antibody neutralization ability, we compared the energy contributions of E484/K484 to the overall binding free energy (Figure 2). In most antibody-RBD systems ( 68\%), the E484 have obvious greater contribution of to the binding free energy than that of K484. For example, the energy contribution of E484 in 7CWO (P17) is $-16.80 \pm 2.35 \mathrm{kcal} / \mathrm{mol}$, while the energy contribution of only $10.24 \pm 3.08 \mathrm{kcal} / \mathrm{mol}$ was found in E484K mutation. By structural analyses, we found that E484 is negatively charged to form a strong electrostatic interaction with antibodies, while K484 is positively charged so that K484 is not conducive to the binding of the antibody (Figure 3 ).

For the five antibody-RBD systems that share roughly identical binding affinity between E484K-RBD and WT-RBD, the difference in the contribution of binding free 
energy between E484 and K484 is also slight. By analyzing the crystal structure (such as 6XE1), we found that the position of E484 deviates from the antibody-RBD interface (Figure 4), which is consistent with the small contribution of E484 to the binding free energy.

For $7 \mathrm{~K} 8 \mathrm{U}$, the interaction between E484 and the antibody is weak. After mutation to $\mathrm{K} 484$, the loop structure on the RBD moves toward the antibody, and more importantly, K484 forms hydrogen bonds with the antibody, leading to a stronger binding ability to the antibody (Figure 5).

For $7 \mathrm{~K} 9 \mathrm{Z}$ (52/298), there is no strong positive charged environment around E484 (Figure 6A). The contribution of E484 and K484 is very small, $0.20 \pm 1.3 \mathrm{kcal} / \mathrm{mol}$ and $0.49 \pm 3.1 \mathrm{kcal} / \mathrm{mol}$, respectively, and the difference between them is also not obvious. By analyzing the energy contribution changes of other residues in the RBD, we found that Q474, T478, E465 and R466 show more contributions in E484K-RBD, exceeding $-1.00 \mathrm{kcal} / \mathrm{mol}$. The conformation changes are due to the K484 mutation causing the position of above five residues to move closer to the antibody, thereby enhancing their interaction with the antibody (Figure 6B).

\section{Per-residue free energy decomposition}

Based on the decomposed binding free energy, we further investigated other residues in the RBD that interact with antibodies. As shown in Figure 7, the proportion of E484 involved in the interaction is $66.67 \%$, indicating that the mutation in this position have an impact in most current antibodies. In addition to E484, there are several other residues that are involved with a relatively high proportion, including F490 (81.48\%), Y449 (81.48\%), Y489 (74.07\%), F486 (70.37\%), Q493 (55.56), V483 (48.15\%), F456 (44.44\%). Interestingly, residues Y449, Y489, F486, Q493 and F456 form stable interactions with ACE2 ${ }^{[15]}$. Therefore, mutations in these sites will seriously affect the spread and infection of the SARS-CoV-2. While E484, which interact with most antibodies, has little contribution to ACE2-RBD interactions. It can be predicted that the E484K mutation will have a relatively small impact on the virus, but it will affect the neutralizing ability of most antibodies which is important for the immune escape. 
Besides, we should also pay attention to residue F490 and V483 which are similar to E484. Mutations in F490 and V483 may also cause immune escape.

\section{CONCLUSION}

Our MD simulations based on the antibody-RBD structure have elucidated the binding free energy changes and the role of E484 in the binding mode. About $71 \%$ antibodies in this studies shows lower binding affinity in E484K-RBD, and among these antibody-RBD complexes, the contribution of E484 is always higher than K484. However, the neutralizing ability of $29 \%$ antibodies are not impaired by E484K mutation. These antibodies that remain neutralization effect may be significant to defeat the virus. Our simulations also predicted that some key residues in the RBD, F490 and V483, are as important as E484 in the binding interface. The mutations of F490 and V483 is also likely to cause immune escape. It should be noted that the spike protein in the above simulation systems is not glycosylated. According to the previous simulation results ${ }^{[15]}$, glycosylation does not affect the binding of ACE2-RBD. Therefore, we can speculate that the glycosylation of spike protein will not affect our current conclusions and we will verify this in subsequent research. 

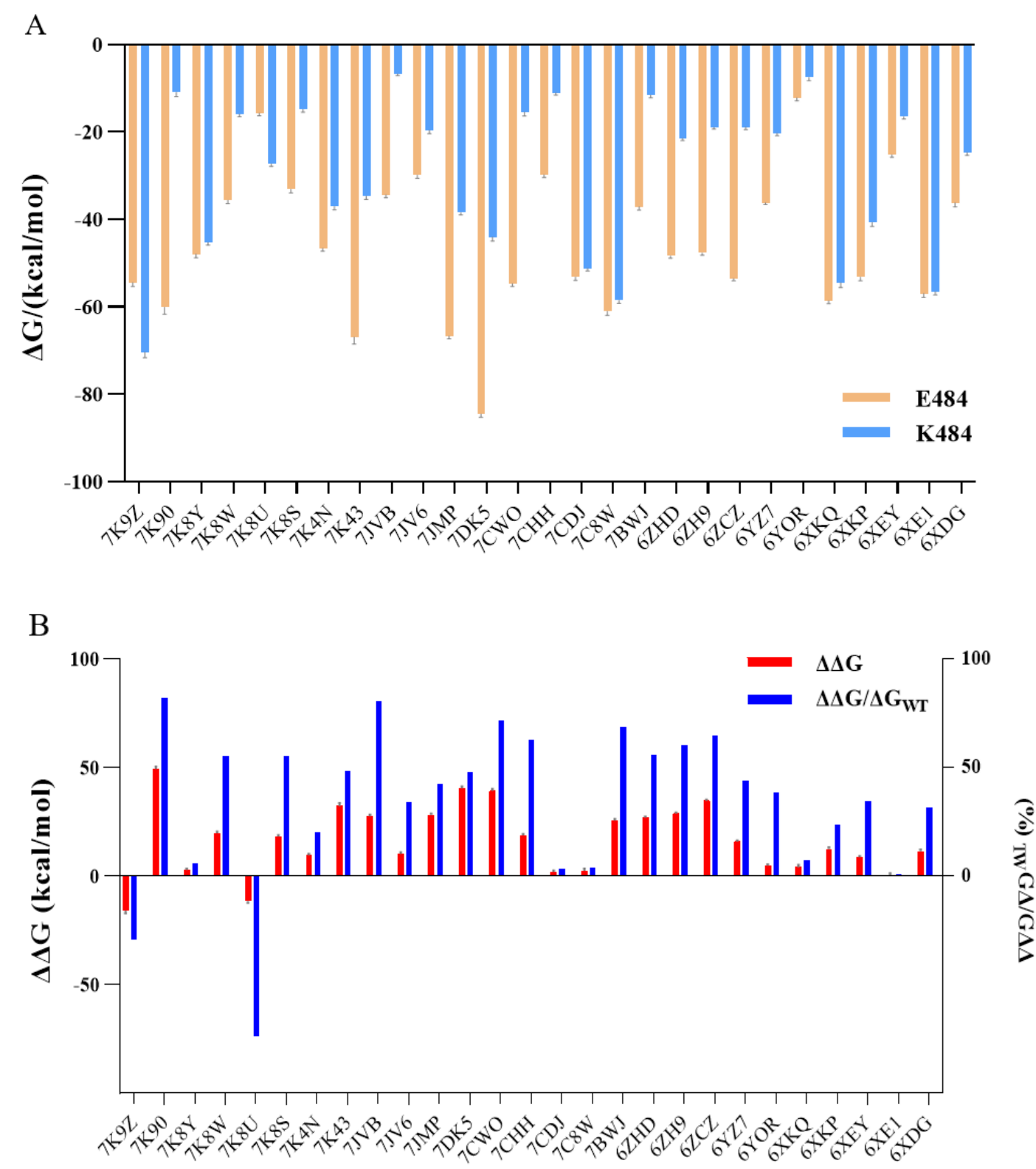

Figure 1. The antibody-RBD binding free energy in WT and E484K mutant. (A) The binding free energy in WT (E484) is colored by orange, and The binding free energy in E484K mutant (K484) is colored by cyan. (B) Changes of the binding free energy between WT and E484K is colored by red $(\Delta \Delta \mathrm{G})$. Percentage of $\Delta \Delta \mathrm{G}$ in $\Delta \mathrm{G}_{\mathrm{WT}}$ is colored by blue. 


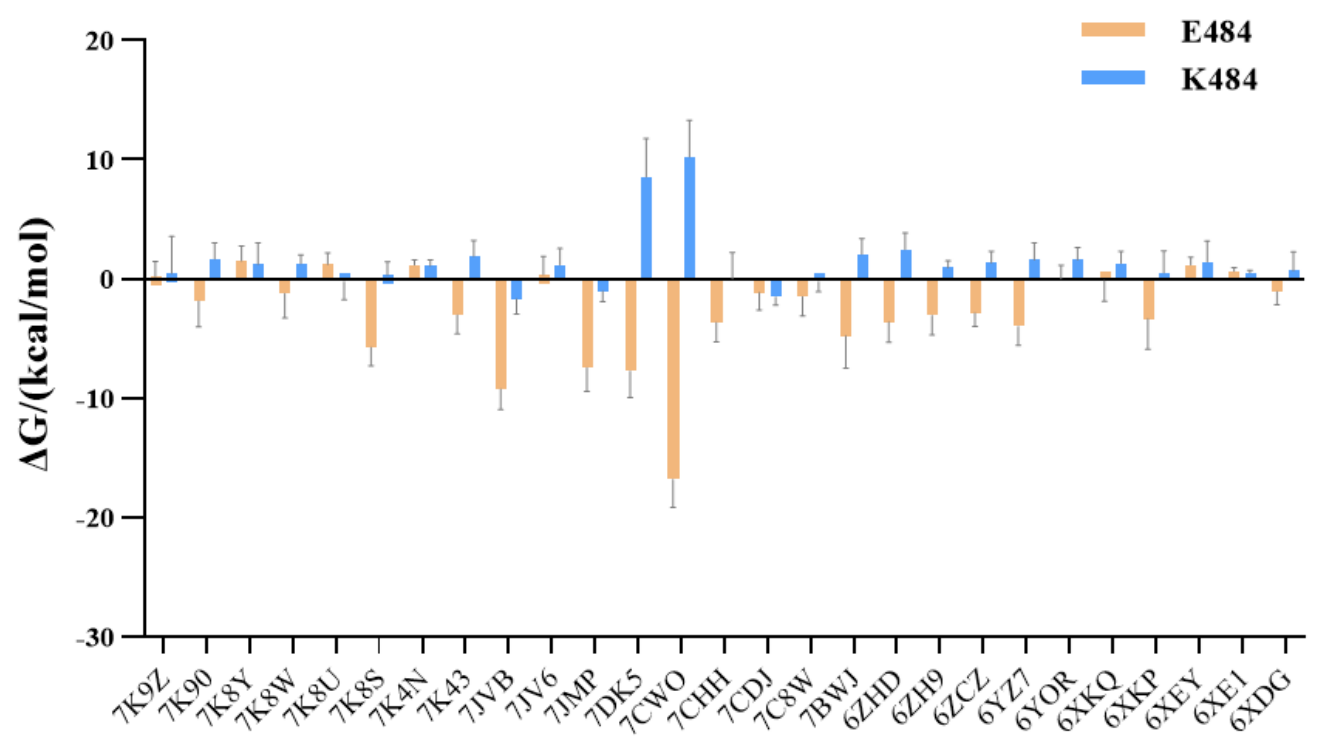

Figure 2. The contribution of E484 and K484 to overall binding free energy.

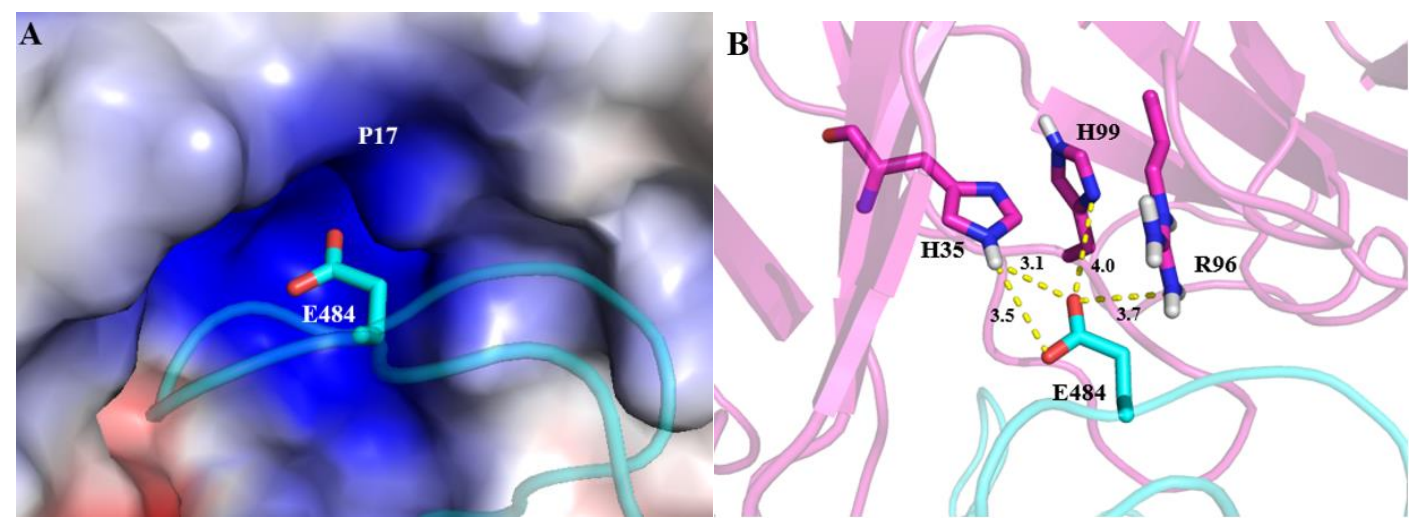

Figure 3. Conformations depicting binding modes of P17-RBD (7CWO). (A) The antibody P17 is showed by vacuum electrostatic potential, blue (positive charge), red (negative charge). The RBD is showed by cartoon (cyan). (B) Interactions of E484 (cyan) and antibody P17 (magenta) in a conformation obtained from 7CWO. 

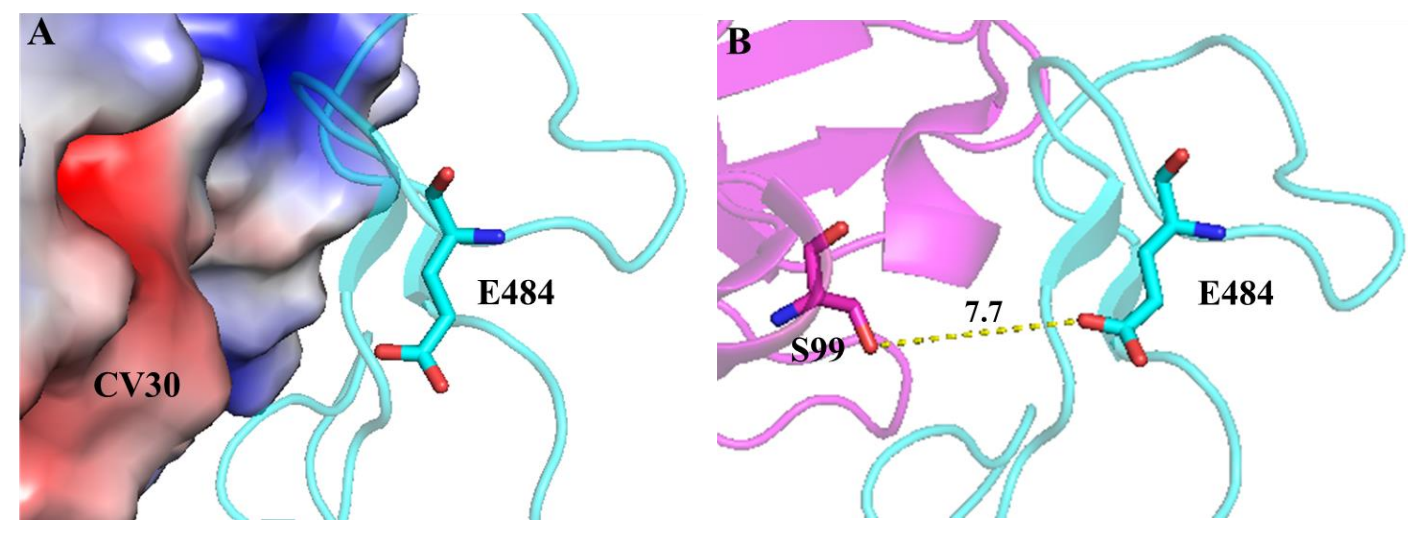

Figure 4. Conformations depicting binding modes of CV30-RBD (6XE1). (A) The antibody CV30 is showed by vacuum electrostatic potential, blue (positive charge), red (negative charge). The RBD is showed by cartoon (cyan). (B) The distance between E484 and CV30 is showed by yellowed dotted line.
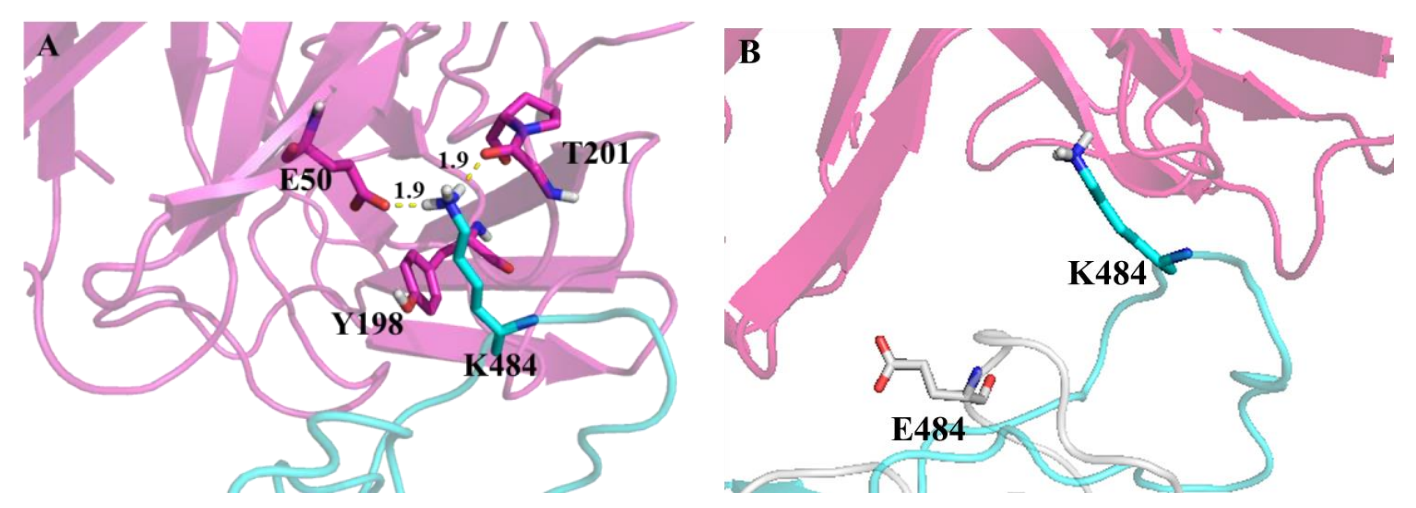

Figure 5. Conformations depicting binding modes of C104-RBD (7K8U). (A) Interactions of K484 (cyan) and antibody C104 (magenta) in a conformation obtained from MD trajectories. (B) Superimposition of conformations of E484 (gray) and K484 (cyan). 

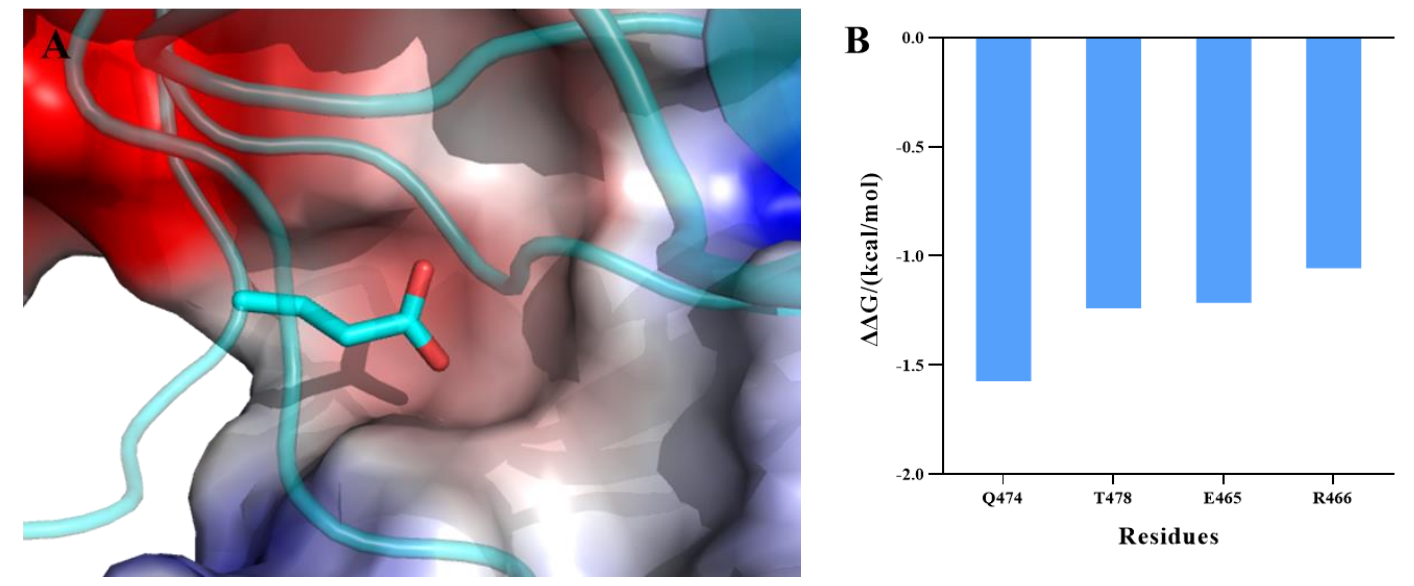

Figure 6. Conformations depicting binding modes of 52/298-RBD (7K9Z). (A) The antibodies 52/98 is showed by vacuum electrostatic potential, blue (positive charge), red (negative charge). The RBD is showed by cartoon (cyan). (B) Key residues of RBD interacting with antibodies 52/98. Each residue changed $\leq-1.00 \mathrm{kcal} / \mathrm{mol}$ to the overall binding free energy.

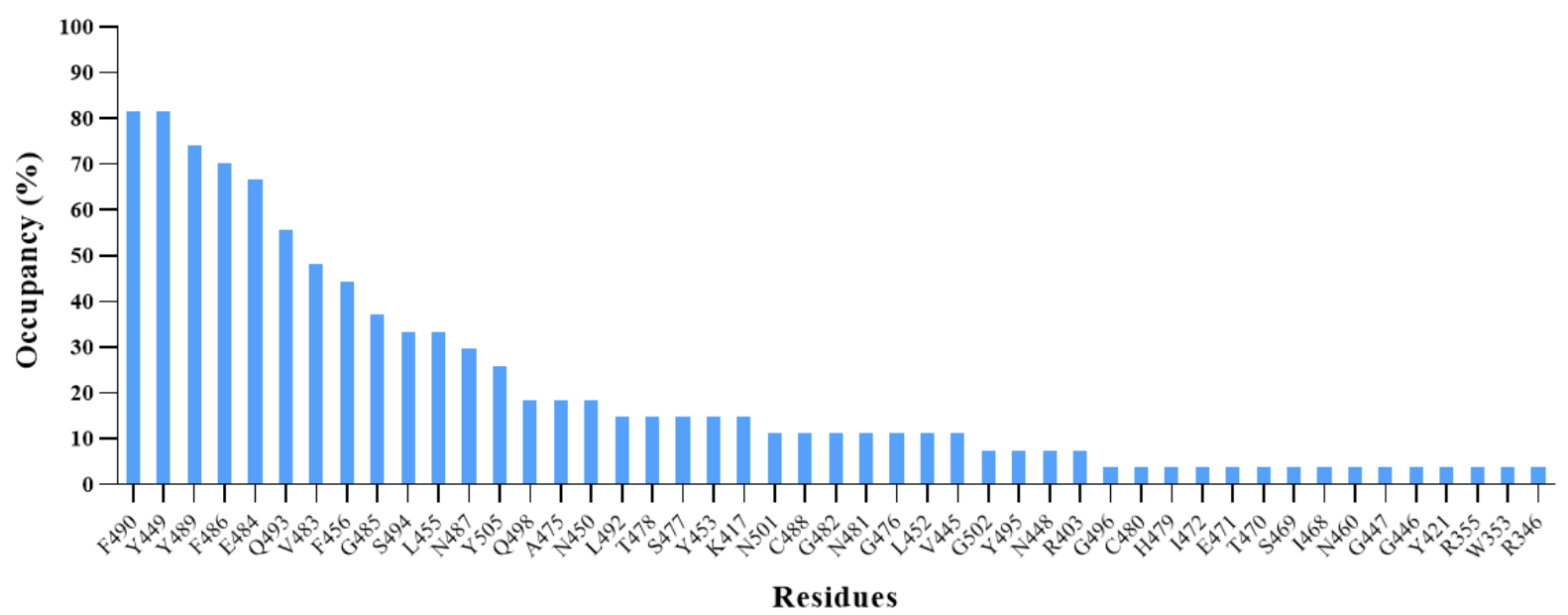

Figure 7. Occupancy of the residues of RBD interacting with antibodies. 


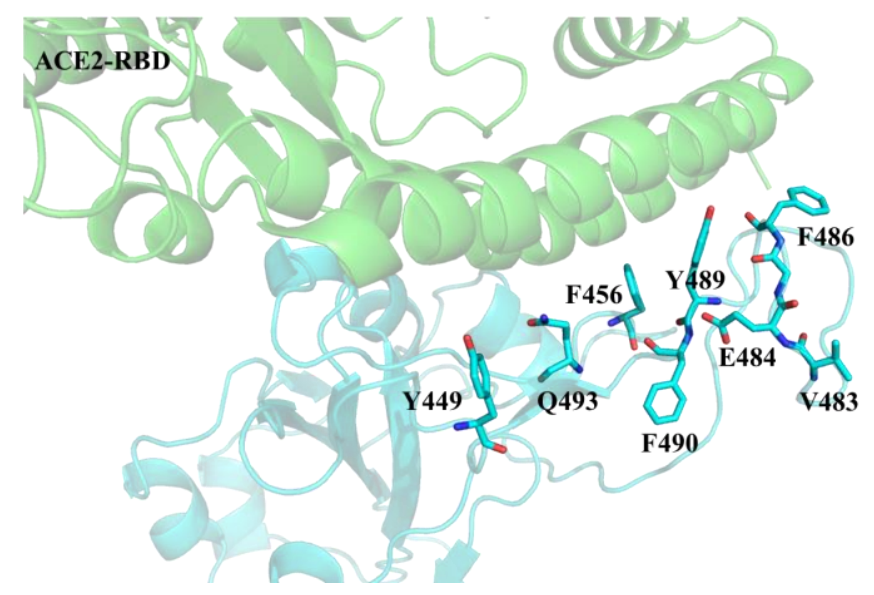

Figure S1. The binding mode of ACE2-RBD 
Table 1 The predicted binding free energy $(\mathrm{kcal} / \mathrm{mol})$ for antibody-RBD

*: Std. Err. of Mean

\begin{tabular}{|c|c|c|c|c|c|c|c|c|}
\hline \multirow{2}{*}{ Antibody Name } & \multirow{2}{*}{ PDB } & \multicolumn{2}{|c|}{ Wild Type } & \multicolumn{2}{|c|}{ E484K-Mutation } & \multicolumn{2}{|c|}{$\Delta \Delta \mathbf{G}$} & \multirow{2}{*}{$\begin{array}{r}\Delta \boldsymbol{\Delta} \mathbf{G} / \Delta \mathbf{G}_{\mathrm{W}} \\
(100 \%)\end{array}$} \\
\hline & & $\Delta \mathbf{G}$ & SEM* & $\Delta \mathbf{G}$ & SEM* & $\Delta \mathbf{G}_{\mathrm{E} 484 \mathrm{~K}}-\Delta \mathbf{G}_{\mathrm{WT}}$ & SEM* & \\
\hline $52 \& 298^{10}$ & $7 \mathrm{K9Z}$ & -54.47 & 0.94 & -70.34 & 1.32 & -15.87 & 1.13 & -29.14 \\
\hline $\mathrm{C}_{144^{7}}$ & $7 \mathrm{~K} 90$ & -60.16 & 1.52 & -10.92 & 0.99 & 49.24 & 1.25 & 81.85 \\
\hline $\mathrm{C}^{121^{7}}$ & $7 \mathrm{~K} 8 \mathrm{Y}$ & -47.97 & 0.80 & -45.27 & 0.64 & 2.70 & 0.72 & 5.63 \\
\hline $19^{7}$ & $7 \mathrm{K8W}$ & -35.62 & 0.75 & -15.94 & 0.61 & 19.68 & 0.68 & 55.26 \\
\hline $\mathrm{C}^{104^{7}}$ & $7 \mathrm{K8U}$ & -15.71 & 0.62 & -27.26 & 0.63 & -11.55 & 0.62 & -73.55 \\
\hline $\mathrm{COO2}^{7}$ & $7 \mathrm{~K} 8 \mathrm{~S}$ & -33.11 & 0.86 & -14.90 & 0.59 & 18.22 & 0.72 & 55.01 \\
\hline S2E129 & 7K4N & -46.60 & 0.67 & -37.08 & 0.67 & 9.52 & 0.67 & 20.44 \\
\hline S2M119 & $7 \mathrm{~K} 43$ & -66.99 & 1.56 & -34.67 & 0.83 & 32.32 & 1.19 & 48.24 \\
\hline Nanobody Nb20 & 7JVB & -34.35 & 0.67 & -6.70 & 0.46 & 27.65 & 0.57 & 80.49 \\
\hline $\mathbf{S 2 H 1 3}^{17}$ & 7JV6 & -29.83 & 0.76 & -19.61 & 0.75 & 10.22 & 0.75 & 34.26 \\
\hline COVA2-39 ${ }^{18}$ & 7JMP & -66.67 & 0.61 & -38.44 & 0.51 & 28.23 & 0.56 & 42.34 \\
\hline $2 \mathrm{H} 2^{19}$ & 7DK5 & -84.55 & 0.73 & -44.05 & 0.87 & 40.50 & 0.80 & 47.90 \\
\hline $\mathbf{P} 17^{20}$ & 7CWO & -54.70 & 0.69 & -15.47 & 0.88 & 39.23 & 0.78 & 71.72 \\
\hline
\end{tabular}




\begin{tabular}{|c|c|c|c|c|c|c|c|c|}
\hline BD-368-2 21 & $7 \mathrm{CHH}$ & -29.81 & 0.67 & -11.03 & 0.54 & 18.77 & 0.60 & 62.98 \\
\hline P2C-1A3 ${ }^{11}$ & 7CDJ & -53.19 & 0.74 & -51.24 & 0.54 & 1.95 & 0.64 & 3.67 \\
\hline $\begin{array}{c}\text { Synthetic } \\
\text { nanobody MR17 }\end{array}$ & $7 \mathrm{C8W}$ & -61.01 & 0.96 & -58.52 & 0.73 & 2.50 & 0.85 & 4.09 \\
\hline P2B-2F6 ${ }^{22}$ & $7 \mathrm{BWJ}$ & -37.09 & 0.80 & -11.59 & 0.59 & 25.50 & 0.70 & 68.75 \\
\hline $\begin{array}{l}\text { Nanobody H11- } \\
\qquad 4^{23}\end{array}$ & 6ZHD & -48.35 & 0.52 & -21.46 & 0.50 & 26.89 & 0.51 & 55.61 \\
\hline Nanobody $^{24}$ & $6 \mathrm{ZH9}$ & -47.75 & 0.47 & -18.93 & 0.47 & 28.82 & 0.47 & 60.35 \\
\hline Nanobody ${ }^{25}$ & $6 Z C Z$ & -53.58 & 0.47 & -18.87 & 0.55 & 34.70 & 0.51 & 64.77 \\
\hline Nanobody $^{26}$ & $6 Y Y Z 7$ & -36.22 & 0.44 & -20.28 & 0.57 & 15.94 & 0.50 & 44.01 \\
\hline IgG H chain ${ }^{27}$ & 6YOR & -12.22 & 0.69 & -7.54 & 0.76 & 4.68 & 0.73 & 38.33 \\
\hline CV07-250 ${ }^{13}$ & 6XKQ & -58.59 & 0.67 & -54.45 & 1.17 & 4.14 & 0.92 & 7.07 \\
\hline CV07-270 ${ }^{13}$ & 6XKP & -53.23 & 0.78 & -40.75 & 0.91 & 12.48 & 0.84 & 23.45 \\
\hline $2-4^{28}$ & 6XEY & -25.24 & 0.51 & -16.57 & 0.51 & 8.67 & 0.51 & 34.35 \\
\hline $\mathrm{CV} \mathrm{B}^{14}$ & 6XE1 & -56.96 & 0.95 & -56.51 & 0.79 & 0.45 & 0.87 & 0.79 \\
\hline REGN10933 $^{8}$ & 6XDG & -36.19 & 0.91 & -24.71 & 0.67 & 11.48 & 0.79 & 31.71 \\
\hline
\end{tabular}




\section{EXPERIMENTAL SECTION}

\section{Preparation of Antibody-RBD Complexes}

The initial structures of the 28 antibody-RBD complexes we used were downloaded from Protein Data Bank and the E484K mutation was built by PyMOL. A cubic box of TIP3P water was used to solvated the complex system, which was extended by $12 \AA$ from the solute. Each system was neutralized by a number of $\mathrm{Na}^{+}$or $\mathrm{Cl}^{-}$. The protein complexes was parameterized by Amber ff14SB force field ${ }^{[29]} \cdot 10,000$ steps of minimization including 5,000 steps of steepest descent minimization and 5,000 steps of conjugate gradient minimization were performed to remove bad contacts formed during the system preparation. Before $0.1 \mathrm{~ns}$ of equilibration in NPT ensemble, each system was heated to $300 \mathrm{~K}$ within $0.2 \mathrm{~ns}$. Sander program in Amber18 was used to run the minimization, heating, and equilibrium simulations with constraints $\left(10 \mathrm{kcal} / \mathrm{mol} / \AA^{2}\right)$ on heavy atoms.

\section{MD simulation}

To assess the dynamic interactions of antibody-RBD, pmemd.cuda in Amber 18 was used to perform $20 \mathrm{~ns}$ MD simulations for antibody-RBD complexes at $300 \mathrm{~K}$. Temperature was controlled by Langevin dynamics, and bonds involving hydrogen atoms were fixed by the SHAKE algorithm ${ }^{[30]}$. The cutoff distance applied for van der Waals interactions was $12 \AA$. And long-range electrostatic interactions was addressed by the particle mesh Ewald method ${ }^{[31]}$.

\section{Binding free energy calculation}

Binding free energy $(\Delta \mathrm{G})$ of antibody-RBD complexes was calculated by MM/GBSA method ${ }^{[32]}$. In this study, the dielectric constants of solute and solvent were set to 1.0 and 80.0 , respectively. The $\mathrm{OBC}$ solvation model $(\mathrm{igb}=5)$ was used. And the binding affinity was further decomposed into energy contribution of each residue in Amber18 (idecomp = 1). 


\section{REFERENCES}

1. World Health Organization. Coronavirus disease (COVID-2019) situation reports. https://www.who.int/emergencies/diseases/novel-coronavirus-2019/situation-reports/ (10 February 2021, date last accessed). 2021.

2. Mahase, E., Covid-19: Novavax vaccine efficacy is $86 \%$ against UK variant and $60 \%$ against South African variant. BMJ 2021, 372, n296.

3. Andreano, E.; Piccini, G.; Licastro, D.; Casalino, L.; Johnson, N. V.; Paciello, I.; Monego, S. D.; Pantano, E.; Manganaro, N.; Manenti, A.; Manna, R.; Casa, E.; Hyseni, I.; Benincasa, L.; $\quad$ Montomoli, E.; Amaro, R. E.; McLellan, J. S.; Rappuoli, R., SARS-CoV-2 escape in vitro from a highly neutralizing COVID-19 convalescent plasma. bioRxiv 2020.

4. Gröhs Ferrareze, P. A.; Franceschi, V. B.; de Menezes Mayer, A.; Caldana, G. D.; Zimerman, R. A.; Thompson, C. E., E484K as an innovative phylogenetic event for viral evolution: Genomic analysis of the E484K spike mutation in SARS-CoV-2 lineages from Brazil. BioRxiv 2021.

5. Wang, P.; Liu, L.; Iketani, S.; Luo, Y.; Guo, Y.; Wang, M.; Yu, J.; Zhang, B.; Kwong, P. D.; Graham, B. S.; $\quad$ Mascola, J. R.; $\quad$ Chang, J. Y.; $\quad$ Yin, M. T.; $\quad$ Sobieszczyk, M.; $\quad$ Kyratsous, C. A.; Shapiro, L.; Sheng, Z.; Nair, M. S.; Huang, Y.; Ho, D. D., Increased Resistance of SARSCoV-2 Variants B.1.351 and B.1.1.7 to Antibody Neutralization. bioRxiv 2021.

6. Starr, T. N.; Greaney, A. J.; Hilton, S. K.; Ellis, D.; Crawford, K. H. D.; Dingens, A. S.; Navarro, M. J.; $\quad$ Bowen, J. E.; Tortorici, M. A.; Walls, A. C.; King, N. P.; Veesler, D.; Bloom, J. D., Deep Mutational Scanning of SARS-CoV-2 Receptor Binding Domain Reveals Constraints on Folding and ACE2 Binding. Cell 2020, 182 (5), 1295-1310 e20.

7. Barnes, C. O.; Jette, C. A.; $\quad$ Abernathy, M. E.; $\quad$ Dam, K. A.; $\quad$ Esswein, S. R.; Gristick, H. B.; Malyutin, A. G.; Sharaf, N. G.; Huey-Tubman, K. E.; Lee, Y. E.; Robbiani, D. F.; Nussenzweig, M. C.; West, A. P., Jr.; Bjorkman, P. J., SARS-CoV-2 neutralizing antibody structures inform therapeutic strategies. Nature 2020, 588 (7839), 682-687.

8. Hansen, J., Studies in humanized mice and convalescent humans yield a SARS-CoV-2 antibody cocktail. Science 2020, 1010-1014. 
9. Tortorici, M. A., Ultrapotent human antibodies protect against SARS-CoV-2 challenge via multiple mechanisms. Science 2020, 370, 950-957.

10. Rujas, E.; Kucharska, I.; Tan, Y. Z.; Benlekbir, S.; Cui, H.; Zhao, T.; Wasney, G. A.; Budylowski, P.; Guvenc, F.; Newton, J. C.; Sicard, T.; Semesi, A.; Muthuraman, K.; Nouanesengsy, A.; Prieto, K.; Bueler, S. A.; Youssef, S.; Liao-Chan, S.; Glanville, J.; Christie-Holmes, N.; Mubareka, S.; Gray-Owen, S. D.; Rubinstein, J. L.; Treanor, B.; Julien, J.P., Multivalency transforms SARS-CoV-2 antibodies into broad and ultrapotent 2 neutralizers. BioRxiv 2020.

11. Wang, X., Zhang, L., Ge, J., Wang, R., Crystal structure of SARS-CoV-2 antibody P2C-1A3 with RBD. 2020.

12. Li, T., Cai, H., Yao, H., Qin, W., Li, D., Structure of sybody MR17 in complex with the SARS-CoV$2 \mathrm{~S}$ receptor-binding domain (RBD). $\mathbf{2 0 2 0 .}$

13. Kreye, J.; Reincke, S. M.; Kornau, H. C.; Sanchez-Sendin, E.; Corman, V. M.; Liu, H.; Yuan, M.; $\quad$ Wu, N. C.; Zhu, X.; Lee, C. D.; Trimpert, J.; Holtje, M.; $\quad$ Dietert, K.; $\quad$ Stoffler, L.; von Wardenburg, N.; van Hoof, S.; Homeyer, M. A.; Hoffmann, J.; Abdelgawad, A.; Gruber, A. D.; Bertzbach, L. D.; Vladimirova, D.; Li, L. Y.; Barthel, P. C.; Skriner, K.; Hocke, A. C.; Hippenstiel, S.; Witzenrath, M.; Suttorp, N.; Kurth, F.; Franke, C.; Endres, M.; Schmitz, D.; Jeworowski, L. M.; Richter, A.; Schmidt, M. L.; Schwarz, T.; Muller, M. A.; Drosten, C.; Wendisch, D.; Sander, L. E.; Osterrieder, N.; Wilson, I. A.; Pruss, H., A Therapeutic Non-selfreactive SARS-CoV-2 Antibody Protects from Lung Pathology in a COVID-19 Hamster Model. Cell 2020, 183 (4), 1058-1069 e19.

14. Hurlburt, N. K.; Wan, Y. H.; Stuart, A. B.; Feng, J.; McGuire, A. T.; Stamatatos, L.; Pancera, M., Structural basis for potent neutralization of SARS-CoV-2 and role of antibody affinity maturation. bioRxiv $\mathbf{2 0 2 0 .}$

15. Peng, C.; Zhu, Z.; Shi, Y.; Wang, X.; Mu, K.; Yang, Y.; Zhang, X.; Xu, Z.; Zhu, W., Computational Insights into the Conformational Accessibility and Binding Strength of SARS-CoV-2 Spike Protein to Human Angiotensin-Converting Enzyme 2. J. Phys. Chem. Lett. 2020, 11 (24), 1048210488.

16. Xiang, Y., Versatile and multivalent nanobodies efficiently neutralize SARS-CoV-2. Science 2020, $1479-1484$. 
17. Piccoli, L.; Park, Y. J.; Tortorici, M. A.; Czudnochowski, N.; Walls, A. C.; Beltramello, M.; Silacci-Fregni, C.; Pinto, D.; Rosen, L. E.; Bowen, J. E.; Acton, O. J.; Jaconi, S.; Guarino, B.; $\quad$ Minola, A.; Zatta, F.; Sprugasci, N.; Bassi, J.; Peter, A.; De Marco, A.; Nix, J.

C.; Mele, F.; Jovic, S.; Rodriguez, B. F.; Gupta, S. V.; Jin, F.; Piumatti, G.; Lo Presti, G.; Pellanda, A. F.; Biggiogero, M.; Tarkowski, M.; Pizzuto, M. S.; Cameroni, E.; HavenarDaughton, C.; Smithey, M.; Hong, D.; Lepori, V.; Albanese, E.; Ceschi, A.; Bernasconi, E.; Elzi, L.; Ferrari, P.; Garzoni, C.; Riva, A.; Snell, G.; Sallusto, F.; Fink, K.; Virgin, H. W.; Lanzavecchia, A.; Corti, D.; Veesler, D., Mapping Neutralizing and Immunodominant Sites on the SARS-CoV-2 Spike Receptor-Binding Domain by Structure-Guided High-Resolution Serology. Cell 2020, 183 (4), 1024-1042 e21.

18. Wu, N. C.; Yuan, M.; Liu, H.; Lee, C. D.; Zhu, X.; Bangaru, S.; Torres, J. L.; Caniels, T. G.; Brouwer, P. J. M.; van Gils, M. J.; Sanders, R. W.; Ward, A. B.; Wilson, I. A., An alternative binding mode of IGHV3-53 antibodies to the SARS-CoV-2 receptor binding domain. bioRxiv 2020.

19. Zhang, C.; Wang, Y.; Zhu, Y.; Liu, C.; Gu, C.; Xu, S.; Wang, Y.; Zhou, Y.; Wang, Y.; Han, W.; Hong, X.; Yang, Y.; Z Zhang, X.; Wang, T.; Xu, C.; Hong, Q.; Wang, S.; Zhao, Q.; Qiao, W.; Zang, J.; Kong, L.; Wang, F.; Wang, H.; Qu, D.; Lavillette, D.; Tang, H.; Deng, Q.; Xie, Y.; Cong, Y.; Huang, Z., Development and structural basis of a two-MAb cocktail for treating SARS-CoV-2 infections. Nature communications 2021, 12 (1), 264.

20. Yao, H.; Sun, Y.; Deng, Y. Q.; Wang, N.; Tan, Y.; Zhang, N. N.; Li, X. F.; Kong, C.; Xu, Y. P.; Chen, Q.; Cao, T. S.; Zhao, H.; Yan, X.; Cao, L.; Lv, Z.; Zhu, D.; Feng, R.; Wu, N.; Zhang, W.; Hu, Y.; Chen, K.; Zhang, R. R.; Lv, Q.; Sun, S.; Zhou, Y.; Yan, R.; Yang, G.; Sun, X.; Liu, C.; Lu, X.; Cheng, L.; Qiu, H.; Huang, X. Y.; Weng, T.; Shi, D.; Jiang, W.; Shao, J.; Wang, L.; Zhang, J.; Jiang, T.; Lang, G.; Qin, C. F.; Li, L.; Wang, X., Rational development of a human antibody cocktail that deploys multiple functions to confer Pan-SARSCoVs protection. Cell Res. 2021, 31 (1), 25-36.

21. Du, S.; Cao, Y.; Zhu, Q.; Yu, P.; Qi, F.; Wang, G.; Du, X.; Bao, L.; Deng, W.; Zhu, H.; Liu, J.; Nie, J.; Zheng, Y.; Liang, H.; Liu, R.; Gong, S.; Xu, H.; Yisimayi, A.; Lv, Q.; Wang, B.; He, R.; Han, Y.; Zhao, W.; Bai, Y.; Qu, Y.; Gao, X.; Ji, C.; Wang, Q.; Gao, N.; Huang, W.; Wang, Y.; Xie, X. S.; Su, X. D.; Xiao, J.; Qin, C., Structurally Resolved SARS-CoV2 Antibody Shows High Efficacy in Severely Infected Hamsters and Provides a Potent Cocktail Pairing 
Strategy. Cell 2020, 183 (4), 1013-1023 e13.

22. Ju, B.; Zhang, Q.; Ge, J.; Wang, R.; Sun, J.; Ge, X.; Yu, J.; Shan, S.; Zhou, B.; Song, S.; Tang, X.; Yu, J.; Lan, J.; Yuan, J.; Wang, H.; Zhao, J.; Zhang, S.; Wang, Y.; Shi, X.; Liu, L.; Zhao, J.; Wang, X.; Zhang, Z.; Zhang, L., Human neutralizing antibodies elicited by SARS-CoV-2 infection. Nature 2020, 584 (7819), 115-119.

23. Clare, D. K., Naismith, J.H., Weckener, M., Vogirala, V.K., H11-H4 bound to Spike. 2020.

24. Huo, J.; Le Bas, A.; Ruza, R. R.; Duyvesteyn, H. M. E.; $\quad$ Mikolajek, H.; Malinauskas, T.;

Tan, T. K.; Rijal, P.; Dumoux, M.; Ward, P. N.; Ren, J.; Zhou, D.; Harrison, P. J.; Weckener, M.; Clare, D. K.; Vogirala, V. K.; Radecke, J.; Moynie, L.; Zhao, Y.; Gilbert-Jaramillo, J.;

Knight, M. L.; Tree, J. A.; Buttigieg, K. R.; Coombes, N.; Elmore, M. J.; Carroll, M. W.; Carrique, L.; Shah, P. N. M.; James, W.; Townsend, A. R.; Stuart, D. I.; Owens, R. J.; Naismith, J. H., Neutralizing nanobodies bind SARS-CoV-2 spike RBD and block interaction with ACE2. Nat. Struct. Mol. Biol. 2020, 27 (9), 846-854.

25. Zhou, D.; Duyvesteyn, H. M. E.; Chen, C. P.; Huang, C. G.; Chen, T. H.; Shih, S. R.; Lin, Y. C.; Cheng, C. Y.; $\quad$ Cheng, S. H.; Huang, Y. C.; Lin, T. Y.; Ma, C.; Huo, J.; Carrique, L.; Malinauskas, T.; $\quad$ Ruza, R. R.; $\quad$ Shah, P. N. M.; $\quad$ Tan, T. K.; $\quad$ Rijal, P.; $\quad$ Donat, R. F.; $\quad$ Godwin, K.; Buttigieg, K. R.; Tree, J. A.; Radecke, J.; Paterson, N. G.; Supasa, P.; Mongkolsapaya, J.; Screaton, G. R.; Carroll, M. W.; Gilbert-Jaramillo, J.; Knight, M. L.; James, W.; Owens, R. J.; Naismith, J. H.; Townsend, A. R.; Fry, E. E.; Zhao, Y.; Ren, J.; Stuart, D. I.; Huang, K. A., Structural basis for the neutralization of SARS-CoV-2 by an antibody from a convalescent patient. Nat. Struct. Mol. Biol. 2020, 27 (10), 950-958.

26. Naismith, J. H., Ren, J., Zhou, D., Zhao, Y., Stuart, D.I., H11-D4, SARS-CoV-2 RBD, CR3022 ternary complex. $\mathbf{2 0 2 0}$.

27. Huo, J.; Zhao, Y.; Ren, J.; Zhou, D.; Duyvesteyn, H. M. E.; Ginn, H. M.; Carrique, L.; Malinauskas, T.; $\quad$ Ruza, R. R.; $\quad$ Shah, P. N. M.; $\quad$ Tan, T. K.; Rijal, P.; Coombes, N.; Bewley, K. R.; Tree, J. A.; $\quad$ Radecke, J.; Paterson, N. G.; Supasa, P.; Mongkolsapaya, J.; Screaton, G. R.; Carroll, M.; Townsend, A.; $\quad$ Fry, E. E.; Owens, R. J.; Stuart, D. I., Neutralization of SARS-CoV-2 by Destruction of the Prefusion Spike. Cell Host Microbe 2020, 28 (3), 445-454 e6.

28. Liu, L.; Wang, P.; Nair, M. S.; Yu, J.; Rapp, M.; Wang, Q.; Luo, Y.; Chan, J. F.; Sahi, V.; Figueroa, A.; Guo, X. V.; Cerutti, G.; Bimela, J.; Gorman, J.; Zhou, T.; Chen, Z.; Yuen, 
K. Y.; Kwong, P. D.; $\quad$ Sodroski, J. G.; Yin, M. T.; Sheng, Z.; Huang, Y.; $\quad$ Shapiro, L.; Ho, D. D., Potent neutralizing antibodies against multiple epitopes on SARS-CoV-2 spike. Nature 2020, 584 (7821), 450-456.

29. Duan, Y. W., C.; Chowdhury, S.; Lee, M. C.; Xiong, G.; Zhang, W.; Yang, R.; Cieplak, P.;; Luo, R. L., T. et al, A point-charge force field for molecular mechanics simulations of proteins based on condensed-phase quantum mechanical calculations. J. Comput. Chem. 2003, 24, 1999-2012.

30. Ryckaert, J. P. C., G.; Berendsen, H. J. C., Numerical integration of the cartesian equations of motion of a system with constraints: molecular dynamics of n-alkanes. J Comput Phys 1997, 23, 327341.

31. Essmann, U. P., L.; Berkowitz, M. L.; Darden, T.; Lee, H.; Pedersen, L. G., A smooth particle mesh Ewald method. J Comput Phys 1995, 103, 8577-8593.

32. Peter A. Kollman, I. M., Carolina Reyes, Bernd Kuhn, Shuanghong Huo, Lillian Chong, Matthew Lee, Taisung Lee, Yong Duan, Wei Wang, Oreola Donini, Piotr Cieplak, Jaysharee Srinivasan, David A. Case, and Thomas E. Cheatham, Calculating Structures and Free Energies of Complex Molecules: Combining Molecular Mechanics and Continuum Models. Acc. Chem. Res. 2000, 33, 889-897. 